\title{
Recent developments in choledochoscopy: technical and clinical advances
}

This article was published in the following Dove Press journal:

Clinical and Experimental Gastroenterology

II May 2016

Number of times this article has been viewed

\author{
Ming-Ming Xu \\ Michel Kahaleh \\ Division of Gastroenterology and \\ Hepatology, Weill Cornell Medical \\ College, Cornell University, New York, \\ NY, USA
}

\begin{abstract}
Peroral cholangioscopy has become an important tool in the diagnosis and treatment of a variety of biliary diseases, ranging from indeterminate biliary strictures to bile duct stones. Although the first cholangioscopy was performed in the 1970s, recent technological advances have provided us with cholangioscopes that yield high-resolution images, possess single-operator capability, and have ultrathin design to allow easier maneuverability and detailed imaging of the biliary tract. We review here the currently available devices for peroral cholangioscopy, their clinical applications, limitations, and complications.
\end{abstract}

Keywords: peroral cholangioscopy, videocholangioscopy, single-operator cholangioscopy, SOC, electrohydraulic lithotripsy

\section{Introduction}

The mainstay method for evaluation of biliary pathology remains endoscopic retrograde cholangiopancreatography (ERCP), which relies on use of fluoroscopy to image the biliary tree. Peroral cholangioscopy (POC) or choledochoscopy allows direct visualization of the pancreatobiliary system for both diagnostic and therapeutic purposes. It has been well studied in the evaluation of indeterminate biliary strictures to improve the diagnostic yield for biliary malignancy. ${ }^{1-6}$ Therapeutically, cholangioscopy has been used for lithotripsy and extraction of large biliary stones. POC was first described in the 1970s, but the first-generation "mother-baby" cholangioscope was significantly limited by its cumbersome design with a need for two operators, scope fragility, limited tip maneuverability, and prolonged procedure time. ${ }^{1,7}$ Recent technological advances have provided us with cholangioscopes yielding high-resolution images and having ultrathin design that allows easier maneuverability and detailed imaging of the biliary tract. We review the currently available devices for POC, their clinical applications, limitations, and complications.

\section{Technical advances Videocholangioscope}

Peroral videocholangioscopy, otherwise known as the "mother-baby" cholangioscope, uses a very slim video cholangioendoscope (CHF-B260; Olympus Medical System, Tokyo, Japan), with an outer diameter of $3.4 \mathrm{~mm}$ and an accessory channel diameter of $1.2 \mathrm{~mm}$, which is introduced through the $4.2 \mathrm{~mm}$ working channel of a therapeutic duodenoscope (TJF 200 series; Olympus Medical System), and the entire system is advanced into the bile duct. ${ }^{8}$ The bile duct is irrigated with saline continuously through 
an accessory channel to maintain good visualization during the examination. Although this system provides good-quality images, with depth of field of 3-20 mm and narrow-band imaging (NBI) capability, its primary limitations prohibiting its widespread use were the need for two endoscopists to perform every examination, its cost, and scope fragility. ${ }^{1,2}$ In one study, ${ }^{2}$ the cholangioscope broke down during its use after 21 cases. Some of these limitations were addressed by the development of the next generation of cholangioscopes, the single-operator cholangioscope.

\section{Single-operator cholangioscopy}

The first single-operator cholangioscope, known as the Spyglass Direct Visualization System (Boston Scientific, Natick, MA, USA), allowed both direct visualization of the biliary tract and directed tissue sampling with a mini forceps (SpyBite). The single-operator cholangioscopy (SOC) system consists of a $10 \mathrm{Fr}, 230 \mathrm{~cm}$ long access-and-delivery catheter (SpyScope), which can be inserted through the standard $4.2 \mathrm{~mm}$ working channel of a therapeutic duodenoscope. The system is introduced into the biliary tree with guide wire assistance after traditional ERCP-based biliary access. A reusable fiber optic probe fits through a $0.9 \mathrm{~mm}$ diameter channel within the SpyScope catheter. A $0.6 \mathrm{~mm}$ irrigation channel in the SpyScope catheter allows continuous flushing of the scope during the procedure to help maintain image clarity. Lastly, a disposable 3 Fr biliary biopsy forceps can be inserted into the $1.2 \mathrm{~mm}$ SpyScope working channel for visually directed biopsies (SpyBite). The optical catheter provides 6,000 pixel images and has four-way tip maneuverability with a 30-degree view in each direction. The light source, video monitor, and irrigation pump are separate components that come with the first-generation system. The newest model is a digital system (Spyglass DS, Boston Scientific) that provides even higher-resolution images and slightly wider field of view with an integrated light source and camera unit.

\section{Direct POC}

An alternative method of POC is the use of an ultraslim endoscope (GIF-XP260NS; Olympus Co, Tokyo, Japan), initially designed for transnasal endoscopy and pediatric use, to directly enter the biliary system. However, a prior biliary sphincterotomy or sphincteroplasty is typically required for direct POC as the outer diameter of these ultraslim endoscopes is $5-6 \mathrm{~mm}$. Biliary cannulation can be technically challenging due to the ultrathin nature of the endoscope, frequent loop formation in the gastric fundus or the duodenum during insertion, and difficulty in anchoring the scope once it is in position. A few techniques have been reported to improve biliary access, including use of a stiff guidewire, intraductal balloon catheter, and overtube balloon-assisted cholangioscopy.

Larghi and Waxman ${ }^{9}$ first reported the use of a 0.035-inchdiameter super-stiff Jagwire (placed into the common bile duct during ERCP) to maintain biliary access after removal of the duodenoscope; the wire was then backloaded onto an ultraslim endoscope, which was advanced into the biliary tree. Wire dislodgement with loss of scope position is a common drawback of this approach with variable reported rates of success, some with $<50 \%$ success. ${ }^{10}$ Alternatively, a 5 Fr balloon catheter can be inserted into the intrahepatic ducts (after guidewire biliary cannulation during ERCP) and inflated to anchor it within the duct and the ultraslim endoscope advanced over the balloon catheter. A small retrospective cohort study ${ }^{10}$ comparing the guidewire versus intraductal balloon approach reported a success rate of $45.5 \%$ versus $95.2 \%$. Although other series have also confirmed a relatively high success rate for the intraductal balloon approach, ${ }^{11,12}$ it is important to note that an anchoring balloon made by Cook Medical (Winston-Salem, NC, USA) was taken off the market after a case of fatal air embolism during cholangioscopy. ${ }^{11-13}$ Lastly, the use of an overtube, similar to those used for single- or double-balloon enteroscopy, to help prevent loop formation during scope placement has been reported, with success rates of $83 \% .^{14-16}$ The overtube approach, however, can be cumbersome as the inner diameter of the overtubes used for enteroscopy is too large for an ultraslim endoscope. A modification with a smaller-diameter overtube for the ultraslim endoscope is still needed.

\section{Clinical applications}

Although ERCP has increasingly moved away from being a purely diagnostic tool toward becoming almost exclusively a therapeutic modality to treat biliary disease, the diagnosis of malignant biliary strictures remains a clinical challenge as our current standard tools, namely, ERCP with brushing and/or biopsy, have poor sensitivity in terms of detection of malignancy. ${ }^{17}$ The development of direct cholangioscopy with the ability to visualize the area of abnormality and conduct direct biopsies of abnormal regions is an advantage of this modality over standard techniques. The other less-common indications for cholangioscopy are listed in Table 1.

\section{Biliary strictures}

An indeterminate stricture is defined by the absence of a visible mass on imaging and/or nondiagnostic results from 
Table I Clinical applications of cholangioscopy

\begin{tabular}{ll}
\hline Diagnostic indications & Therapeutic indications \\
\hline Indeterminate biliary stricture & Intraductal lithotripsy \\
Staging ampullary neoplasm & Retrieval of migrated \\
(extension into biliary tree) & pancreatobiliary stents \\
Staging cholangiocarcinoma & Endoscopic tumor ablation therapy \\
Evaluation of cystic lesion of the & Foreign body removal \\
biliary tree & \\
Evaluation of hemobilia & Guidewire placement \\
Unexplained intraductal filling defect & Transpapillary gallbladder drainage \\
Posttransplant biliary complications & \\
\hline
\end{tabular}

initial ERCP with brushing and/or biopsy. ERCP with brushing has a reported sensitivity of detecting malignancy between $23 \%$ and $56 \%$ despite the high specificity of $>95 \% .{ }^{18-21}$ One of the possible causes of the poor diagnostic yield of fluoroscopically guided brushing and biopsy is the imprecise targeting of the stricture because of the location of the stricture and/or difficulty with sampling in a tight area, especially around the hilum. ${ }^{22,23}$ Cholangioscopy offers the advantage of direct visual inspection of the suspected stricture to assess for visual characteristics of malignancy and target biopsies in those areas of interest. Various imaging characteristics have been proposed for malignant-appearing strictures on cholangioscopy, including dilated and tortuous "tumor vessels", intraductal nodules or papillary projections, ulcerated or infiltrative stricture, and irregular vascular patterns with irregular mucosal surface. ${ }^{23}$ The strongest feature suggestive of malignancy is the presence of dilated and tortuous vessels with a reported specificity and positive predictive value of $100 \%{ }^{3,5,24} \mathrm{In} \mathrm{Kim}$ et al's $\mathrm{s}^{5}$ prospective study of 63 patients with indeterminate strictures undergoing Spyglass cholangioscopy, using the tumor vessel sign as a predictor of malignancy had a sensitivity of $61 \%$ and specificity of $100 \%$ for malignancy. However, there have been some concerns raised about the interobserver agreement and reliability in assessing for malignancy based on the visual impression component alone. In a retrospective study $^{25}$ involving multiple, blinded, expert endoscopists evaluating video clips of 38 cholangioscopies conducted for biliary strictures, the interobserver agreement on malignant versus benign strictures was only fair, although at the time of the study, no standard visual impression criteria had been established and the features used were slightly different than the more recently suggested criteria. The largest prospective, multicenter, observational study of the operating characteristics of the SOC system by Chen et $\mathrm{al}^{6}$ included 226 patients with biliary strictures (not all were cytology negative) and it reported sensitivity, specificity, positive predictive value, and negative predictive value for malignancy of $78 \%, 82 \%$, $80 \%$, and $80 \%$, respectively, based on the visual impression of stricture etiology. Visual impression had higher sensitivity compared to visually targeted biopsy, which was only $47 \%$, although biopsy specificity was much higher at $98 \%$ with a positive predictive value of $100 \%$. Other smaller prospective series of patients with indeterminate strictures have shown similar results, with sensitivity reported to be as high as $95 \%$ and specificity 79\% for SOC visual impression and SpyBite biopsies exhibiting $82 \%$ sensitivity and $82 \%$ specificity. ${ }^{26}$

The other novel component of the SOC system is the ability to perform visually directed biopsies. Only one published study ${ }^{27}$ to date has directly compared the diagnostic yield of SpyBite biopsy to brush cytology and fluoroscopybased endobiliary biopsy. Although the study sample was small (26 patients), it clearly demonstrated the superior performance of cholangioscopy-guided biopsy to standard tissue sampling technique, with sensitivity for malignancy of $76.5 \%$ versus $29.4 \%$ for forceps biopsy, as well as diagnostic accuracy of $84.6 \%$ versus $53.8 \%$ for forceps biopsy. ${ }^{27}$ These results reflect the ability of cholangioscopy to better target the abnormal areas for biopsy relative to fluoroscopy-based sampling. Direct POC using ultraslim endoscope may have an advantage in providing larger biopsy samples than the miniforceps used in SOC, but there are currently no head-tohead data comparing the diagnostic yield of these two types of cholangioscopy.

One special population of patients in whom the evaluation of biliary strictures is particularly difficult is the group with primary sclerosing cholangitis (PSC). Cholangioscopy has been studied in a relatively small number of patients with PSC and further investigation of its role in this population is still needed. Although SOC can be helpful in identifying coincidental choledocholithiasis that presents as a dominant stricture, in many cases, the chronic inflammatory nature of PSC makes the visual distinction between cholangiocarcinoma (CCA) and a benign inflammatory stricture difficult. ${ }^{28}$ One prospective series ${ }^{29}$ that included 53 patients with PSC with dominant strictures evaluated by both standard ERCP and cholangioscopy found the visual impression of cholangioscopy to have higher sensitivity ( $92 \%$ versus $66 \%$ ), specificity ( $93 \%$ versus $51 \%$ ), and accuracy ( $93 \%$ versus $55 \%$ ) for CCA compared to ERCP cholangiogram impression. Large, multicenter studies using uniform visual impression criteria are still needed to confirm these published results.

Several adjunctive imaging techniques have also been investigated for concurrent use with SOC, including NBI and chromocholangioscopy, borrowing from the application of 
these imaging techniques to detect dysplasia in other regions of the gastrointestinal tract. NBI uses the shorter bandwidth of spectral transmittance for optical imaging, resulting in the preferential enhancement of the pit and capillary patterns of the superficial gastrointestinal mucosa. ${ }^{30}$ In the biliary tract, NBI-enhanced cholangioscopy has been used to better delineate and detect neovascularization associated with CCA, compared to white light cholangioscopy. ${ }^{31}$ The largest prospective, multicenter case series ${ }^{32}$ of patients who underwent POC with NBI for indeterminate strictures included 38 patients and found the diagnostic sensitivity of NBI-enhanced cholangioscopy for CCA to be $96 \%$, specificity to be $80 \%$, and accuracy to be $92 \%$. However, a significant limitation of NBI cholangioscopy is that both bile and blood will appear dark or dark red on NBI, making their differentiation difficult and necessitating time-consuming lavage of the biliary tree to achieve high-quality images. ${ }^{31}$ Additionally, although NBI may improve the visualization of tumor vascularization, NBI-directed biopsies did not actually increase the diagnosis of malignancy or dysplasia compared to standard POC in one prospective study ${ }^{33}$ of patients with PSC, raising questions about the applicability of this technique.

Chromocholangioscopy is done with the injection of methylene blue $(0.15 \%-0.1 \%)$ via an accessory channel into the biliary tract, followed by continuous lavage of the biliary epithelium to observe differences in surface staining between neoplastic and nonneoplastic tissues. The small number of case series describing this technique shows that normal biliary epithelium usually stains homogeneously, whereas neoplastic mucosa has heterogeneous uptake of the dye, resulting in patchy staining, and acutely inflamed tissue stains intensely dark blue. ${ }^{34,35}$ Both of these image-enhanced cholangioscopy techniques hold promising possibilities for better ways to visualize the contrast between normal and cancerous tissues in the biliary tract but are both still in the investigational stages of use, are not widely available, and require expertise in their image interpretation.

\section{Bile duct stones}

Although conventional ERCP with mechanical lithotripsy and stone retrieval remains the first-line therapy for bile duct stones, cholangioscopy-guided electrohydraulic lithotripsy (EHL) or laser lithotripsy has become a well-established technique for large stones and those that fail ERCP-based removal. Cholangioscopy can also detect bile duct stones that were missed on cholangiogram during ERCP. ${ }^{26,28}$ Cholangioscopy-guided lithotripsy has several distinct advantages: it can be performed during conventional ERCP as an adjunctive therapy, the thinner probes can be maneuvered to reach intrahepatic stones in otherwise-difficult locations, and it allows direct visualization of ductal clearance and examination for residual stones after stone extraction. The success and safety of cholangioscopy-guided EHL have been well established in both retrospective and prospective studies, ${ }^{6,36-38}$ with stone clearance rates between $90 \%$ and 100\%. Cholangioscopyguided laser has also been described; in one series ${ }^{39}$ of patients failing previous ERCP stone removal, complete stone clearance was achieved in $97 \%$ of patients with laser lithotripsy.

\section{Other applications of choledochoscopy}

Because choledochoscopy provides unprecedented visual and direct access to the biliary system, it has allowed endoscopists to expand its use to some unique clinical problems, including evaluation of cystic lesions of the bile duct, ${ }^{40}$ tumor staging in ampullary cancers, ${ }^{41}$ unexplained hemobilia, ${ }^{42}$ and evaluation of post-liver-transplant strictures. ${ }^{43}$ Therapeutically, cholangioscopy has been used in transpapillary gallbladder drainage, ${ }^{44}$ retrieval of migrated biliary stents, ${ }^{45}$ foreign body removal from the biliary tree, ${ }^{46}$ and tumor ablation therapies using argon plasma coagulation and intraductal radiotherapy, ${ }^{47}$ as well as photodynamic therapy. ${ }^{48}$

\section{Complications and limitations}

The major limitations to consider when using cholangioscopy are the need for biliary sphincterotomy to advance the system into the biliary tree and the possible increase in rate of complications. The largest prospective, multicenter study ${ }^{6}$ of diagnostic and therapeutic cholangioscopy reported serious procedural complications in $7.5 \%$ and $6.1 \%$ of patients undergoing diagnostic cholangioscopy and cholangioscopyguided EHL, respectively, with the most frequent adverse event being cholangitis, which occurred in $3.1 \%$ of patients. A later study by Sethi et $\mathrm{al}^{49}$ confirmed a complication rate of $7.0 \%$ when cholangiopancreatoscopy was performed versus the conventional ERCP complication rate of $2.9 \%$, with the difference attributed to a higher incidence of cholangitis; the rates of pancreatitis and perforation were not significantly different between the two groups. ${ }^{49}$ Use of prophylactic antibiotics is therefore recommended when cholangioscopy is performed. Finally, direct cholangioscopy is currently only used in select centers because of the high cost of the equipment and expertise required for its use.

\section{Conclusion}

The advent of direct cholangioscopy marks a significant step forward in the diagnosis and therapy of biliary diseases. 
It has allowed endoscopists to visualize the biliary system in unprecedented detail and deliver targeted therapy. POC is a promising adjunctive tool in the evaluation of indeterminate biliary strictures, which remains one of the most difficult clinical conundrums in biliary endoscopy. One of the main areas for future research is development of refined visual criteria for malignancy in SOC. It also remains to be seen whether cholangioscopy can gain widespread adoption given its current high cost, the level of expertise required for use, and other advanced imaging tools that are also in use or are being developed.

\section{Disclosure}

Dr Kahaleh has received consulting fee from Boston Scientific and research funding from Boston Scientific, Gore, Pinnacle, Cook, Maunakea and Xlumina. Dr Xu reports no conflicts of interest in this work.

\section{References}

1. Igarashi Y, Okano N, Ito K, Suzuki T, Mimura T. Effectiveness of peroral cholangioscopy and narrow band imaging for endoscopically diagnosing the bile duct cancer. Dig Endosc. 2009;21:S101-S102.

2. Parsi MA, Stevens T, Collins J, Vargo JJ. Utility of a prototype peroral video cholangioscopy system with narrow-band imaging for evaluation of biliary disorders (with videos). Gastrointest Endosc. 2011;74:1148-1151.

3. Nimura Y, Kamiya J. Cholangioscopy. Endoscopy. 1998;30:182-188.

4. Osanai M, Itoi T, Igarashi Y, et al. Peroral video cholangioscopy to evaluate indeterminate bile duct lesions and preoperative mucosal cancerous extension: a prospective multicenter study. Endoscopy. 2013;45:635-642.

5. Kim HJ, Kim MH, Lee SK, Yoo KS, Seo DW, Min YI. Tumor vessel: a valuable cholangioscopic clue of malignant biliary stricture. Gastrointest Endosc. 2000;52:635-638.

6. Chen YK, Parsi MA, Binmoeller KF, et al. Single-operator cholangioscopy in patients requiring evaluation of bile duct disease or therapy of biliary stones (with videos). Gastrointest Endosc. 2011;74:805-814.

7. Takekoshi T, Takagi K. Retrograde pancreatocholangioscopy [in Japanese with English abstract]. Gastroenterol Endosc. 1975;17: 678-683.

8. Igarashi Y, Okano N, Sato D, et al. Peroral cholangioscopy using a new thinner videoscope (CHF-B260). Dig Endosc. 2005;17:S57-S59.

9. Larghi A, Waxman I. Endoscopic direct cholangioscopy by using an ultra-slim upper endoscope: a feasibility study. Gastrointest Endosc. 2006;63:853-857.

10. Moon JH, Ko BM, Choi HJ, et al. Intraductal balloon-guided direct peroral cholangioscopy with an ultraslim upper endoscope (with videos). Gastrointest Endosc. 2009;70:297-302.

11. Meves V, Ell C, Pohl J. Efficacy and safety of direct transnasal cholangioscopy with standard ultraslim endoscopes: results of a large cohort study. Gastrointest Endosc. 2014;79:88-94.

12. Pohl J, Meves VC, Mayer G, Behrens A, Frimberger E, Ell C. Prospective randomized comparison of short-access mother-baby cholangioscopy versus direct cholangioscopy with ultraslim gastroscopes. Gastrointest Endosc. 2013;78:609-616.

13. Efthymiou M, Raftopoulos S, Antonio Chirinos J, May GR. Air embolism complicated by left hemiparesis after direct cholangioscopy with an intraductal balloon anchoring system. Gastrointest Endosc. 2012;75:221-223.
14. Choi HJ, Moon JH, Ko BM, et al. Overtube-balloon-assisted direct peroral cholangioscopy by using an ultra-slim upper endoscope (with videos). Gastrointest Endosc. 2009;69:935-940.

15. Takaoka M, Shimatani M, Ikeura T, et al. Diagnostic and therapeutic procedure with a short double-balloon enteroscope and cholangioscopy in a patient with acute cholangitis due to hepatolithiasis. Gastrointest Endosc. 2009;70:1277-1279.

16. Matsushita M, Shimatani M, Takaoka M, Okazaki K. Effective peroral direct cholangioscopy with an ultraslim gastroscope in combination with a short double-balloon enteroscope for altered GI anatomy. Gastrointest Endosc. 2012;76:1075.

17. Navaneethan U, Njei B, Lourdusamy V, Konjeti R, Vargo JJ, Parsi MA. Comparative effectiveness of biliary brush cytology and intraductal biopsy for detection of malignant biliary strictures: a systematic review and meta-analysis. Gastrointest Endosc. 2015;81:168-176.

18. Burnett AS, Calvert TJ, Chokshi RJ. Sensitivity of endoscopic retrograde cholangiopancreatography standard cytology: 10-y review of the literature. J Surg Res. 2013;184:304-311.

19. Ponchon T, Gagnon P, Berger F, et al. Value of endobiliary brush cytology and biopsies for the diagnosis of malignant bile duct stenosis: results of a prospective study. Gastrointest Endosc. 1995;42:565-572.

20. Glasbrenner B, Ardan M, Boeck W, Preclik G, Möller P, Adler G. Prospective evaluation of brush cytology of biliary strictures during endoscopic retrograde cholangiopancreatography. Endoscopy. 1999;31:712-717.

21. Jailwala J, Fogel EL, Sherman S, et al. Triple-tissue sampling at ERCP in malignant biliary obstruction. Gastrointest Endosc. 2000;51:383-390.

22. De Bellis M, Sherman S, Fogel E, et al. Tissue sampling at ERCP in suspected malignant biliary stricture. Gastrointes Endosc. 2002; 56:552-561

23. Seo DW, Lee SK, Yoo KS, et al. Cholangioscopic findings in bile duct tumors. Gastrointest Endosc. 2000;52:630-634.

24. Itoi T, Neuhaus H, Chen YK. Diagnostic value of image-enhanced video cholangiopancreatoscopy. Gastrointest Endosc Clin N Am. 2009;19:557-566.

25. Sethi A, Widmer J, Shah NL, et al. Interobserver agreement for evaluation of imaging with single operator choledochoscopy: what are we looking at? Dig Liver Dis. 2014;46:518-522.

26. Ramchandani M, Reddy DN, Gupta R, et al. Role of single-operator peroral cholangioscopy in the diagnosis of indeterminate biliary lesions: a single-center, prospective study. Gastrointest Endosc. 2011;74:511-519.

27. Draganov PV, Chauhan S, Wagh MS, et al. Diagnostic accuracy of conventional and cholangioscopy-guided sampling of indeterminate biliary lesions at the time of ERCP: a prospective, long-term follow-up study. Gastrointest Endosc. 2012;75:347-353.

28. Awadallah NS, Chen YK, Piraka C, Antillon MR, Shah RJ. Is there a role for cholangioscopy in patients with primary sclerosing cholangitis? Am J Gastroenterol. 2006;101:284-291.

29. Tischendorf JJ, Krüger M, Trautwein C, et al. Cholangioscopic characterization of dominant bile duct stenoses in patients with primary sclerosing cholangitis. Endoscopy. 2006;38:665-669.

30. Gono K, Obi T, Yamaguchi M, et al. Appearance of enhanced tissue features in narrow-band endoscopic imaging. J Biomed Opt. 2004;9:568-577.

31. Itoi T, Sofuni A, Itokawa F, et al. Peroral cholangioscopic diagnosis of biliary tract diseases by using narrow-band imaging (with videos). Gastrointest Endosc. 2007;66:730-736.

32. Osanai M, Itoi T, Igarashi Y, et al. Peroral video cholangioscopy to evaluate indeterminate bile duct lesions and preoperative mucosal cancerous extension: a prospective multicenter study. Endoscopy. 2013;45:635-642.

33. Azeem N, Gostout CJ, Knipschield M, Baron TH. Cholangioscopy with narrow-band imaging in patients with primary sclerosing cholangitis undergoing ERCP. Gastrointest Endosc. 2014;79:773-779.

34. Hoffman A, Kiesslich R, Bittinger F, Galle PR, Neurath MF. Methylene blue-aided cholangioscopy in patients with biliary strictures: feasibility and outcome analysis. Endoscopy. 2008;40:563-571. 
35. Maetani I, Ogawa S, Sato M, Igarashi Y, Sakai Y, Shibuya K. Lack of methylene blue staining in superficial epithelia as a possible marker for superficial lateral spread of bile duct cancer. Diagn Ther Endosc. 1996;3:29-34.

36. Chen YK, Pleskow DK. SpyGlass single-operator peroral cholangiopancreatoscopy system for the diagnosis and therapy of bile-duct disorders: a clinical feasibility study (with video). Gastrointest Endosc. 2007;65:832-841.

37. Farrell JJ, Bounds BC, Al-Shalabi S, et al. Single-operator duodenoscope-assisted cholangioscopy is an effective alternative in the management of choledocholithiasis not removed by conventional methods, including mechanical lithotripsy. Endoscopy. 2005;37: 542-547.

38. Piraka C, Shah RJ, Awadallah NS, Langer DA, Chen YK. Transpapillary cholangioscopy-directed lithotripsy in patients with difficult bile duct stones. Clin Gastroenterol Hepatol. 2007;5:1333-1338.

39. Patel SN, Rosenkranz L, Hooks B, et al. Holmium-yttrium aluminum garnet laser lithotripsy in the treatment of biliary calculi using single-operator cholangioscopy: a multicenter experience (with video). Gastrointest Endosc. 2014;79:344-348.

40. Warmann S, Meier PN, Kardorff R, Fuchs J. Cystic echinococcosis with perforation into the biliary tract in an eight-year-old girl. Eur J Pediatr Surg. 2002;12:134-137.

41. Cennamo V, Luigiano C, Fabbri C, et al. Cholangioscopy using a new type of cholangioscope for the diagnosis of biliary tract disease: a case series. Endoscopy. 2012;44:878-881.
42. Prasad GA, Abraham SC, Baron TH, Topazian MD. Hemobilia caused by cytomegalovirus cholangiopathy. Am J Gastroenterol. 2005;100:2592-2595.

43. Siddique I, Galati J, Ankoma-Sey V, et al. The role of choledochoscopy in the diagnosis and management of biliary tract diseases. Gastrointest Endosc. 1999;50:67-73.

44. Barkay O, Bucksot L, Sherman S. Endoscopic transpapillary gallbladder drainage with the SpyGlass cholangiopancreatoscopy system. Gastrointest Endosc. 2009;70:1039-1040.

45. Kantsevoy SV, Frolova EA, Thuluvath PJ. Successful removal of the proximally migrated pancreatic winged stent by using the SpyGlass visualization system. Gastrointest Endosc. 2010;72:454-455.

46. Ransibrahmanakul K, Hasyagar C, Prindiville T. Removal of bile duct foreign body by using spyglass and spybite. Clin Gastroenterol Hepatol. 2010;8(1):e9.

47. Lu XL, Itoi T, Kubota K. Cholangioscopy by using narrow-band imaging and transpapillary radiotherapy for mucin-producing bile duct tumor. Clin Gastroenterol Hepatol. 2009;7:e34-e35.

48. Talreja JP, DeGaetani M, Sauer BG, Kahaleh M. Photodynamic therapy for unresectable cholangiocarcinoma: contribution of single-operator cholangioscopy for targeted treatment. Photochem Photobiol Sci. 2011;10:1233-1238.

49. Sethi A, Chen YK, Austin GL, et al. ERCP with cholangiopancreatoscopy may be associated with higher rates of complications than ERCP alone: a single-center experience. Gastrointest Endosc. 2011;73:251-256
Clinical and Experimental Gastroenterology

\section{Publish your work in this journal}

Clinical and Experimental Gastroenterology is an international, peerreviewed, open access journal, publishing all aspects of gastroenterology in the clinic and laboratory, including: Pathology, pathophysiology of gastrointestinal disease; Investigation and treatment of gastointestinal disease; Pharmacology of drugs used in the alimentary tract;

\section{Dovepress}

Immunology/genetics/genomics related to gastrointestinal disease. This journal is indexed on CAS. The manuscript management system is completely online and includes a very quick and fair peer-review system. Visit http://www.dovepress.com/testimonials.php to read real quotes from published authors. 